The two types shown in this table were very much harder to distinguish this year than in 1907, and many okra-leafed plants may have been counted as intermediates. Had this condition been due to cross-pollination by insects with the adjacent Upland types, it should have left the distinction between the two forms as well defined as in 1907 .

It seems to me that the close correspondence between tables I and III argues against any great amount of crossing by insects, and that the whole set of figures show a fairly close approximation to those required by Mendel's law. Moreover, it does not seem to hold out any very great hopes of fixing intermediate types of lint, should Merdel's law also apply to that character.

\title{
NOTES ON COTTON BREEDING IN NORTHERN GEORGIA.
}

By H. A. Allakd.

LOW-LINTED AND LINTLESS COTTON-PLANTS.

No two plants in a cotton field ever meet with identical environmental conditions. As a result we note infinite variability in all the population as to size, shape, leaf position, etc., down to the finest details of structure. Other differences are of a more definite and stable character, and persist to a great degree, independently of immediate environmental influences. These plants may be grouped into more or less distinct classes or types, according to the size and shape of bolls, earliness, character of foliage, lint, etc. From the point of view of profitable cotton culture, not all these types are equally valuable. Some among these meet the requirements of particular soils, regions and purposes much better than others, and a few are at all times worthless and decidedly detrimental to the best interests of the growers.

With respect to the amount of lint on the seed, cotton plants show great variability. Scanty-linted or even quite lintless plants now and then occur in the best of cotton fields, and perpetuate these undesirable cha:acters very uniformly. In nearly every field of cotton these lowlinted types are more or less in evidence, but especially in those fields plantcd from mixed ard unselected seed.

In the fall of 1907, the writer selected a striking specimen of lintless plant in one of the most productive cotton fields in North Georgia. This plant had only 5.5 per cent of lint on strictly smooth, black seed. In connection with the work of cotton breeding and field-demonstrative 
tests begun in north Georgia in 1908, the progeny of this plant proved most interesting and instructive. A progeny of 38 plants was obtained, and the lint per cent of each plant accurately determined and plotted.

Fig. 1. It will be seen that the minimum per cent of lint is somewhat less than 2 per cent. The mass of the population falls in classes considerably lower in lint per cent than that of the parent plant. The maximum lint per cent reached 28 per cent, but occurred on a rather striking and abnormal aberration from the general distribution of the progeny, possibly due to the crossing influences of insects.

Fig. 2 shows the opened and unopened bolls of the individual plant with the minimum lint per cent of 1.8 per cent. As the illustration shows, the seeds of this plant were practically naked, and dropped in a mass to the ground as each boll opened. In some instances, the seeds of each lock were firmly stuck or cemented in a mass, just as are the seeds of the kidney cottons.

In other characters than lint per cent or covering, this progeny was remarkably uniform. Without exception every plant had strictly smooth, black seeds. Also in size, shape and the four locked character of bolls, earliness, thinness of foliage, etc., every plant was alike with only small deviations.

Fig. 3. shows the typical boll shape of the lintless type of plant. The bolls are markedly pointed, four locked, and of ten more or less irregular. The sides are usually much flattened forming planes, or they may be depressed between the middle and the apex. This type of boll is quite characteristic of the lintless plants, and enables one to identify them pretty accurately in the field, even before any bolls have opened.

Fig. 4 shows contrasting degrees of covering in the progeny plotted in Fig. 1. T-12-1 has a little over 1 per cent of lint, while T-12-7 has over 28 per cent of lint.

The appearance of scanty-linted varieties is not an unusual feature in any cotton field, but the causes that produce them are as yet too obscure for explanation.

Occasionally a plant with abundant lint will produce one or more bolls that have almost no lint on the seed.

Fig. 5 shows such a boll variation in a plant of the smooth seeded progeny T-6-1. A single boll had only 2.9 per cent of lint as compared with 24.2 per cent of lint from the other bolls.

In connection with cotton breeding and field demonstrations conducted in north Georgia in 1908, the lintless plants and their.progenies proved to be some of the strongest arguments in favor of careful selection 
FIGURE 1

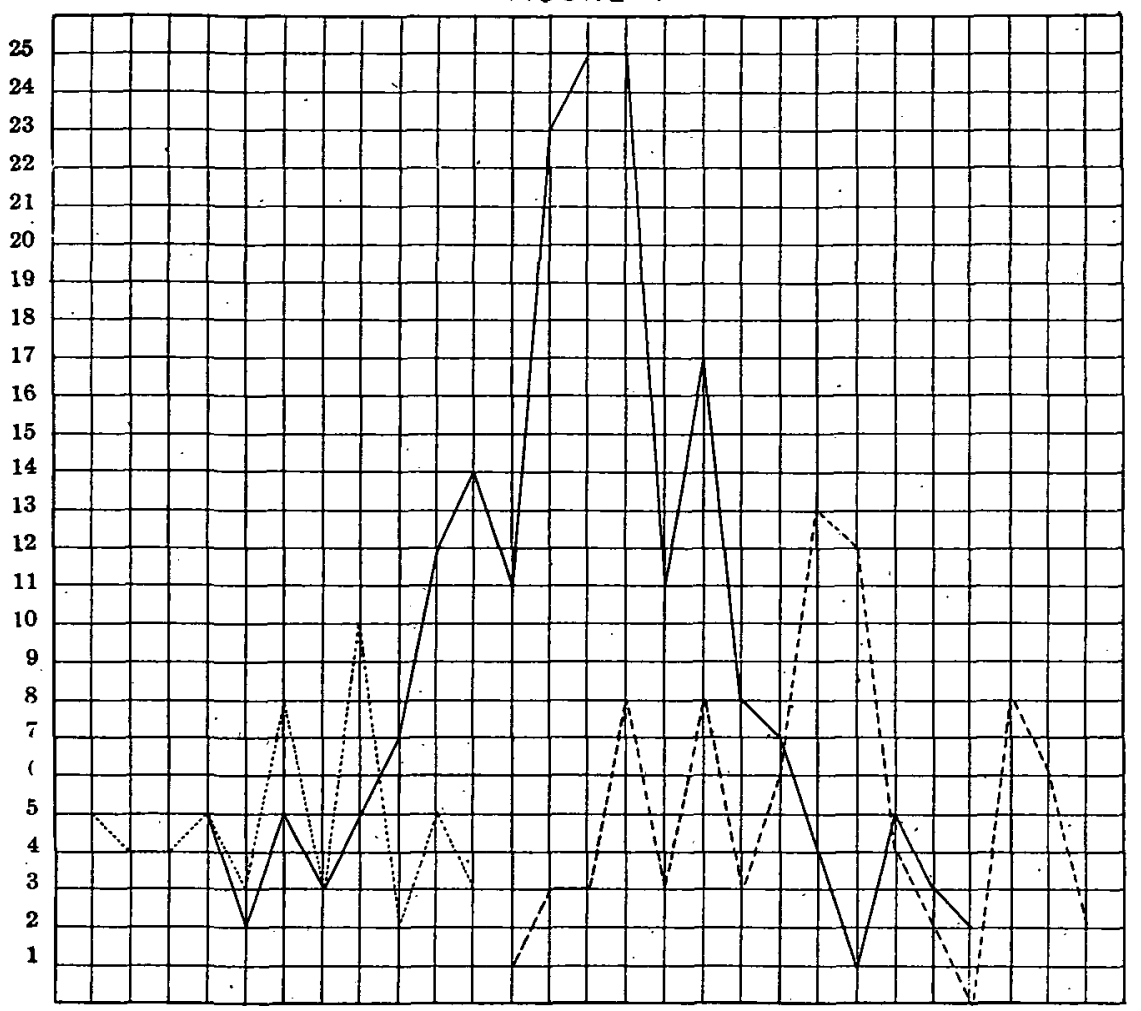

$\begin{array}{lllllllllllllllllllllllllll}49 & 50 & 51 & 52 & 53 & 54 & 55 & 56 & 57 & 58 & 59 & 60 & 61 & 62 & 63 & 64 & 65 & 66 & 67 & 68 & 69 & 70 & 71 & 72 & 73 & 74 & 75\end{array}$

$\sim N \omega \in N$ UARIATES

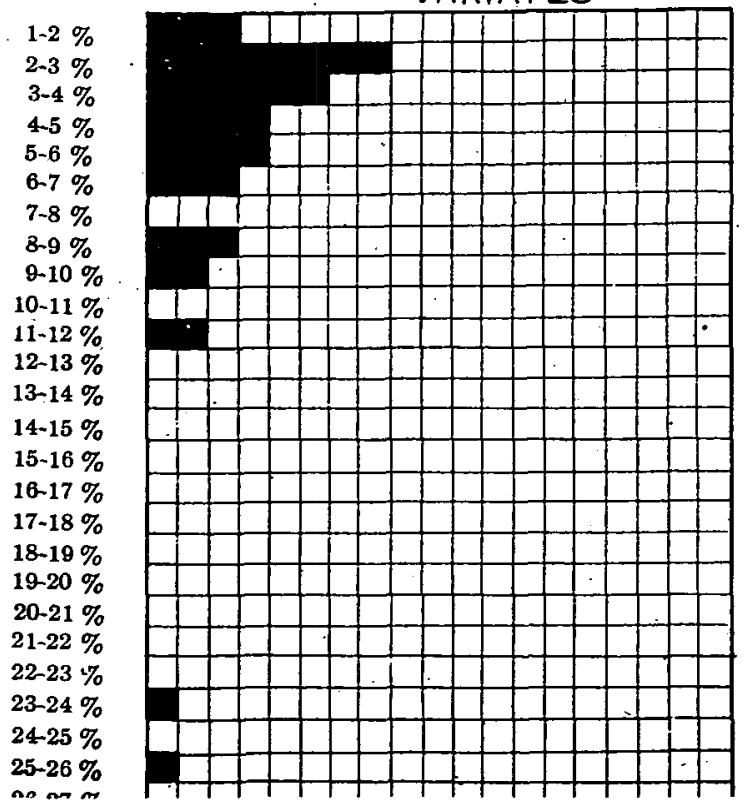


COMMITTEE ON COTTON BREEDING.

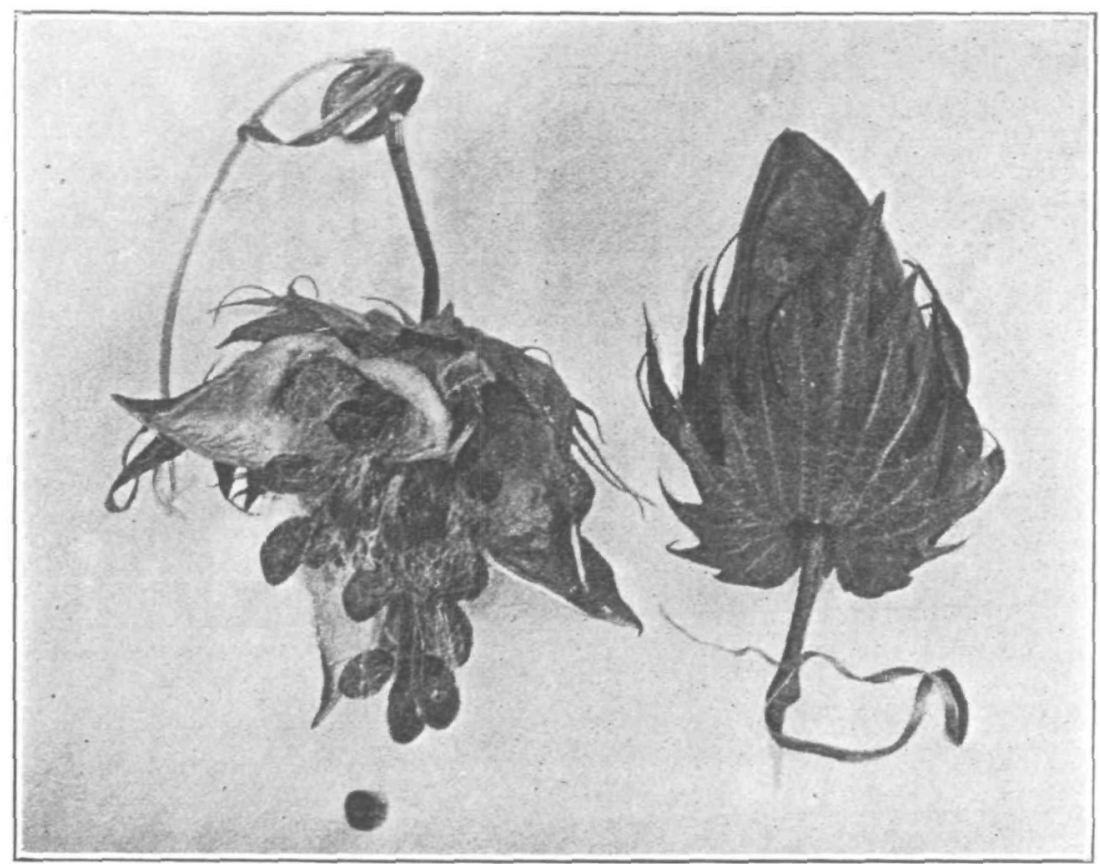

Fia. 2 TyPICAL bOLLS OF THE LINTLESS PROGENY.

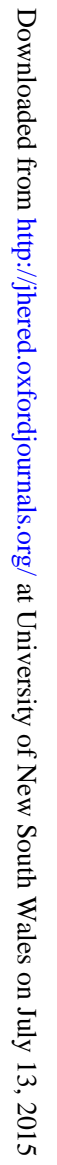

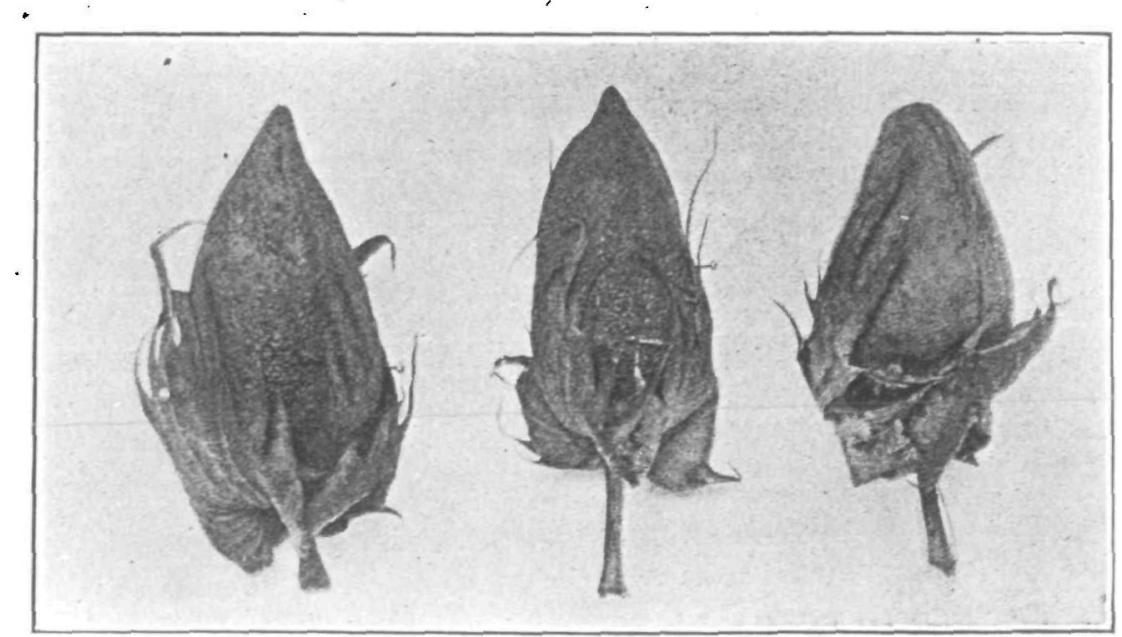

FTG. 3 TYPICAL bolls OF THE LINTLESS PROGENY. 
to secure better crops. At the same time they were convincing proofs to many indifferent and skeptical growers that such plants propagate their undesirable characters, or "repeat" themselves as the grower expresses it in his own vernacular.

\section{A TEST OF PURE SEED SELECTION.}

Careful field selection prevents in a great measure the perpetuation of undesirable types in a crop. In cotton, the extremely low-linted types

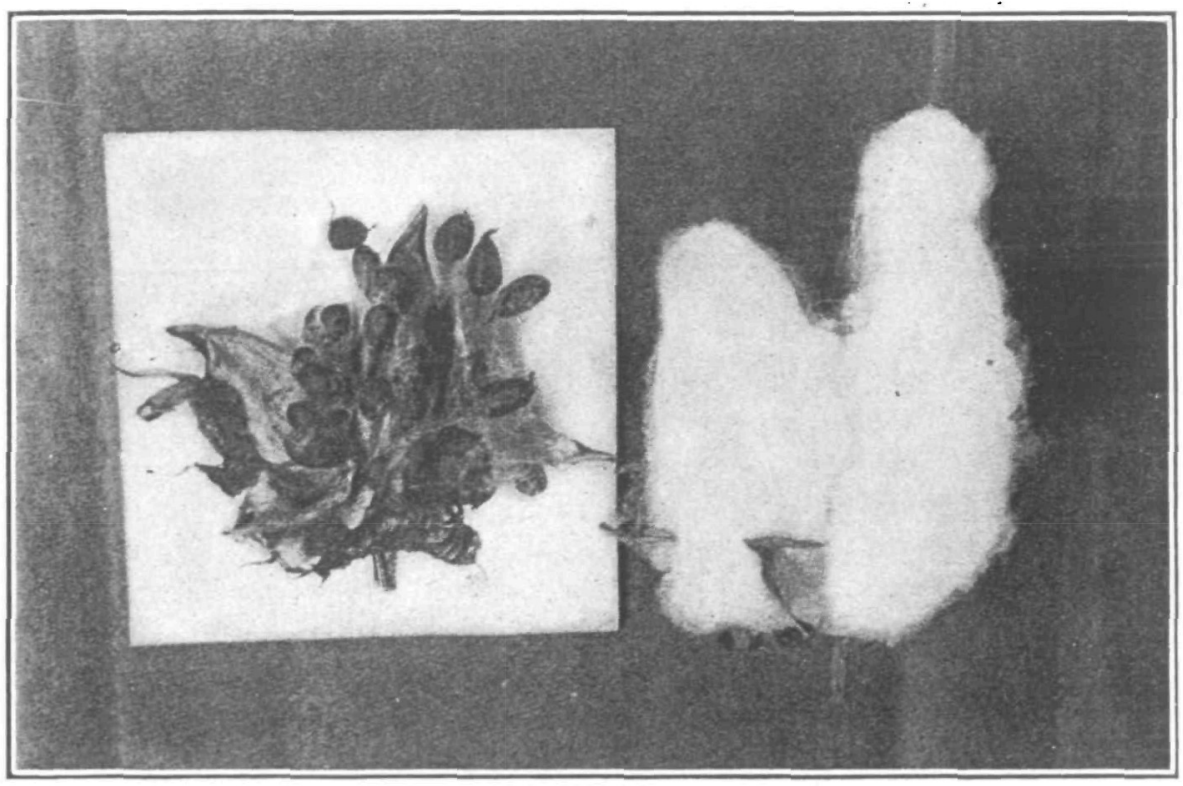

FIG. 4 BOLL TO THE RIGHT T-12-1. BOLL TO THE LEFT T-12-7.

are readily identified by every intelligent grower, and judged as detrimental to the possibilities of maximum production. In fact if a variety characterized by well covered, fuzzy seed is grown, it would appear that smooth-seeded plants may well be considered suspicious and undesirable variations away from usefulness. An experiment consisting of pure seed selection from the seed pile itself brought out some interesting results along this line. A quantity of general seed from a widely known bragpatch crop grown in northern Georgia, was carried to the laboratory, and there separated into several very distinct grades according to degree of fuzziness, color of fuzz, etc. 
Grade A included strictly smooth, black seeds, care being taken to exclude even those seeds which showed only a few hairs around the beak.

Grade $\mathrm{H}$ included only those seeds known as the semi-smooth green type. These seeds were covered with a very scanty green fuzz or veil, beneath which the black seed coat showed more or less distinctly.

Grade $\mathrm{J}$ included all dark green, heavily-tufted seeds.

Grade L included all purely white, heavily-tufted seeds.

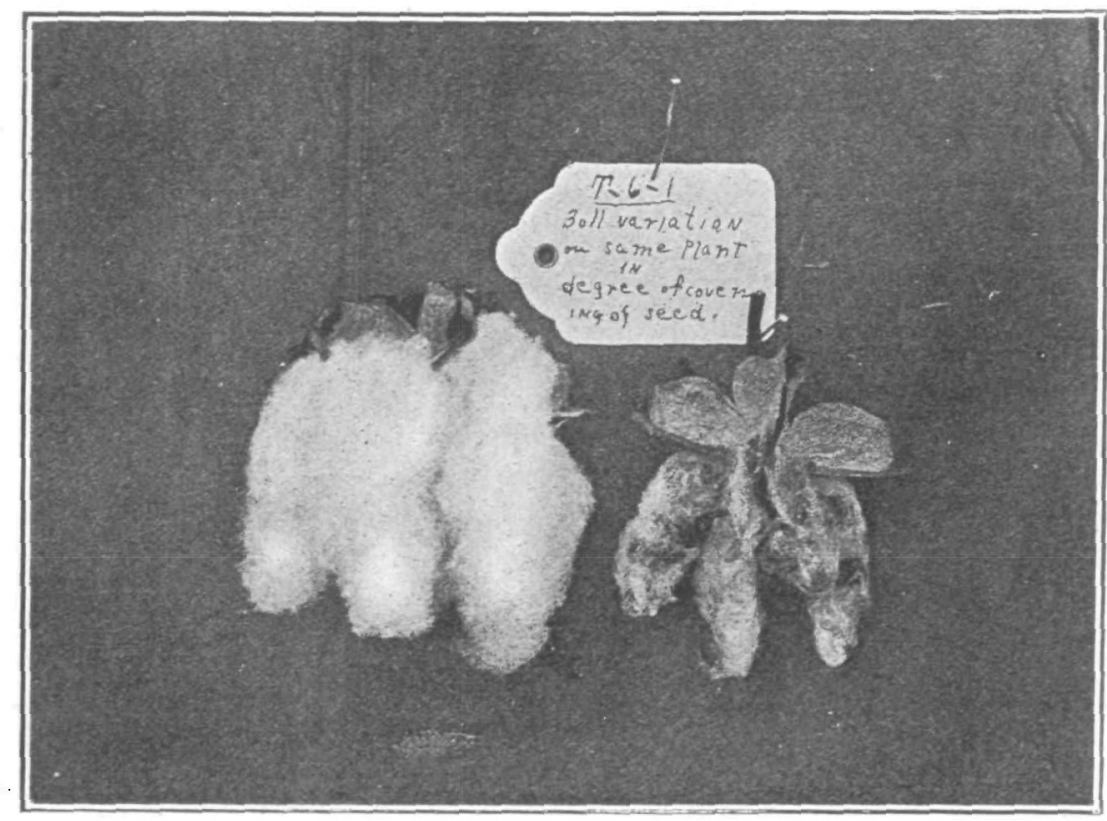

FIG. 5

These grades were carefully planted in separate rows in north Georgia during the season of 1908.

A comparison of the smooth seeded type and the jwhite-tufted type. Grade $\mathcal{L}$ is of considerable interest. A row of thirty plants was obtained from the Grade A, smooth seeded, and a row of twenty-six plants from the Grade $\mathrm{L}$ white-tufted type. A glance revealed striking differences throughout the rows. Low lint per cent, small, pointed, four-locked bolls, etc., characterized nearly every plant of the former, while the latter was very distinct in having white tufted seeds, abundant covering and 
very large bolls. From a picking of an equal number of bolls from each plant in the separate rows, the percentage of lint was carefully obtained.

Grade A, smooth, gave 23 per cent of lint. Grade L, white tufted, gave 32.5 per cent of lint. Grade J, dark green tufted, gave 32.7 per cent of lint. Grade $\mathrm{H}$, semi-smooth, gave 32.8 per cent of lint.

With respect to the transmission of the characteristics, the following data was obtained, especially for grades $\mathrm{A}$ and $\mathrm{L}$.

Grade A, a row of thirty plants obtained-seeds smooth. Twentyfour plants with strictly smooth, black seed (a few hairs on a few seeds in two plants).

One plant with a few hairs scattered uniformly over the seed coat.

Two plants with a ring of fine, almost unnoticeable hairs around the beak.

1 plant with semi-smooth; and with a heavily tufted white fuzz around the beak.

1 plant with seeds nearly smooth, but with a heavily tufted white fuzz around the beak.

1 plant with seeds nearly smooth, but with heavily tufted greenish fuzz around the beak.

Grade L. A row of 26 plants from seeds, white, heavily tufted.

20 plants with heavily tufted seeds, white or grayish.

1 plant with very short brownish fuzz on the seed.

1 plant with semi-smooth, white seed.

1 plant with dark green, heavily tufted seeds.

2 plants with grayish green heavily tufted seeds.

1 plant with semi-smooth green seeds.

Grade $J$, a row of thirty plants from seeds dark green, heavily tufted. Every plant with more or less green tufted seed, mostly dark green, heavily tufted. A few plants with semi-smooth greenish seed.

Grade $\mathrm{H}$, thirty plants in the row from semi-smooth, green seed. Most of these plants with seed semi-smooth, or heavily tufted at the tip, and more or less distinctly green. No plants with really smooth seed. A number with heavily tufted, dark green fuzz, but none distinctly white and heavily tufted.

Among those plants in the smooth seeded grade A row, the minimum lint per cent was 8.1 and the maximum 33 per cent. In small size, pointed shape and four-locked character of bolls, plants of the Grade A type were very distinct from the larger, more rounded, five-locked bolls of Grade L. The average boll diameter of each plant for each grade, 
platted to hundredths of an inch, shows this very striking inferiority in boll size of the smooth-seeded type. See Fig. 6. The vertical series of figures represents the diameter-magnitudes in excess of an inch, as no bolls examined fell below one inch in diameter.

Where careful selection in the field is observed, these undesirable, smooth seeded, low-linted types and other worthless types cannot vitiate the general average of excellence by perpetuation of their characteristics. With cotton and with many other crops, probably the greatest gains toward usefulness along any line, have been secured and maintained by

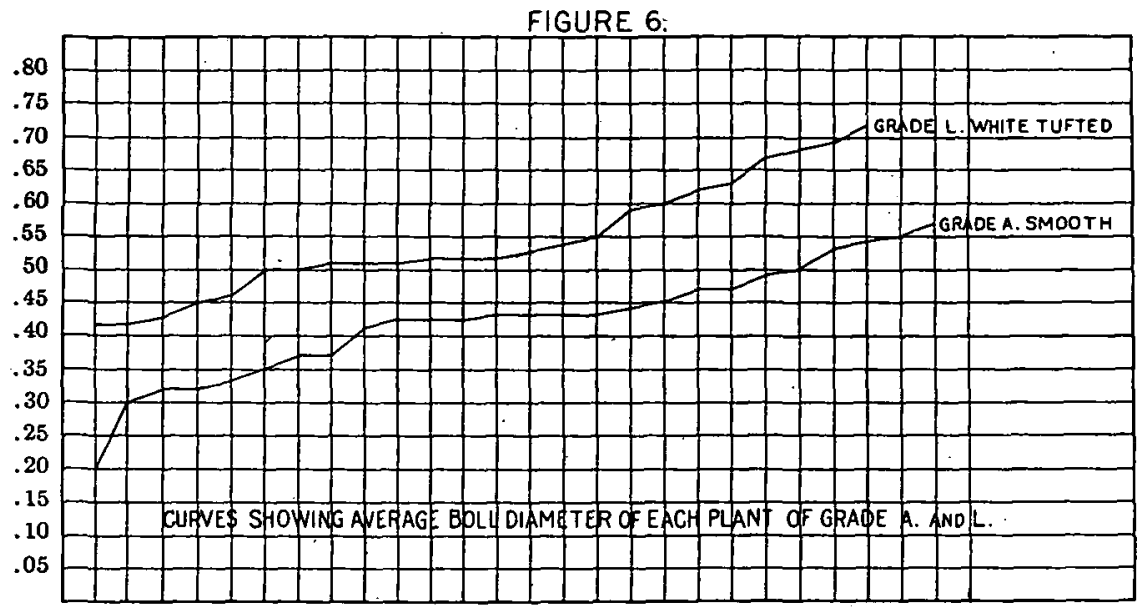

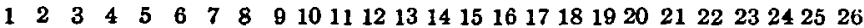

FIG. 6

the process of segregating the best types to themselves. This process of isolating and exploiting certain really promising plants, all over the cotton belt, has for many years, been going on, and has been one of the most powerful and far repaching factors in the general improvement of the crop. In this manner new and superior types have completely superseded less useful types from time to time over large areas of the entire cotton belt.

Where the factor of selection is entirely ignored, all types both good and bad, are free to multiply and intermingle until an apparent degeneration has taken place. In cotton which is to a great extent self-fertilized, and in wholly self-fertilized plants, as wheat and barley, this deteriora-. 
tion need not be an inherent tendency. The original strain or type of maximum usefulness still exists as before, but relatively in less abundance due to the multiplication at the same time of less useful types which persist when selection ceases and under some conditions, where a strain of high specific excellence has been isolated and is grown without further attention to seed selection, under the richest field conditions, an apparent degeneration may appear to take place more rapidly than where grown under poorer conditions. This is due in part to the enormously greater seed production of the larger, better nourished plants, enabling every individual to propagate itself far more rapidly than where the plants are small and seed production lessened. This is especially true in cotton, where the average boll production per plant on poor land may be little more than three or four, as compared with many times that number on the most fertile soils. Types of especial excellence are relatively uncommon, and where all variations are allowed to propagate under conditions promoting maximum seed-production, these soon become swamped by the relatively greater number of inferior sorts.

The writer found the greatest number of low-linted and quite lintless plants, in one of the most productive cotton fields grown in north Georgia, from mixed and unselected seed. In this field there existed very promising týpes of cotton, but there were very few, when compared with the entire population embracing all degrees of variability down to quite worthless types.

There is a tendency with some to regard these fields as exceptionally fine grounds for the so-called origination of better varieties from the most promising types. So far as the average individuality of this field is concerned, a segregation of the best types of selection does bring about striking results from the start. Whether or not a gradual cumulative selection alone could ever accomplish the same results from an inferior type has not been satisfactorily proved. At any rate the process would be a very slow one, and necessitate the waste of much time. The isolation and multiplication of the best types has been and probably is today the surest means of securing and maintaining decided improvement in any direction.

$$
\text { THE "MAKING" PERIOD OF A COTTON BOLL. }
$$

A cotton boll 'makes' in the period of time from the day of blossoming to the cracking of the boll. Cotton growers almost universally hold the opinion that this period is longest for the earliest blossoms of the season, and gradually shortens as the period of blossoming advances 
toward sutumn. Questioning the correctness of this assumption, the writer, during the season of 1908 , while carrying on cotton breeding investigations in northern Georgia, gathered some data bearing on this question.

At the beginning of the blossoming season, many hundreds of cotton blossoms were tagged and labelled with the day of opening. This was continued at intervals for nearly a month. As these bolls which set approached maturity, the plants were visited daily to determine the date of cracking of each tagged boll. In order to make this determination as uniform as possible, each nearly mature boll was lightly pressed at the apex between the fingers. If the segments easily split apart under this light pressure, the date of cracking was set down on the tag, which was then removed. In this way several varieties were studied and data of considerable interest obtained bearing on the question of the number of days required to make cotton bolls throughout the 'summer.

That habit of the cotton plant which causes it to shed nearly all its bolls, oftentimes for a considerable time, following unfavorable weather conditions, etc., makes it almost impossible to get an even distribution of data for any period. However, the data obtained is sufficient to show that the blossoms appearing earliest in the season make their bolls much more quickly than those appearing later in the summer.

The days of blossoming of several hundred tagged bolls of the Keenan variety were as follows: July, 11, 12, 13, 14, 15, 16, 26, 27, 28, 29, 30, 31 and August 2, 3 and 4. Grouping this period into intervals of three days each, the average increase in the number of days required to make bolls is as follows:

Blossoms opening July 11,12 and 13 required an average of $52: 8$ days

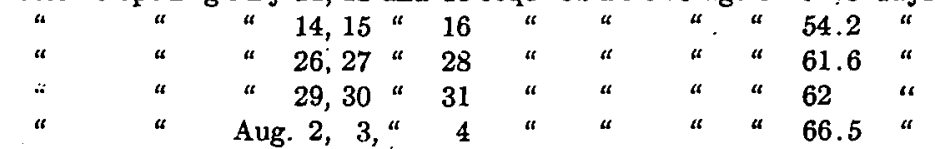

The accompanying curves Fig. 1 show very strikingly this relation between the successive intervals of blossoming and the rapidly increasing number of days required to make bolls as the summer advances.

The vertical column of figures represents the number of variates.

The horizontal series of figures represent the day periods within which bolks were "made."

The first dotted line represents blossoms opening on the days July $11,12,13,14,15$, and 16 . 
The continuous line represents blossoms opening on the days July $26,27,28,29,30$ and 31 .

The broken line represents blossoms opening on the days August 2, 3 and 4.

As will be seen from the chart, among the earliest blossoms of the season opening on the days July 11 through July 16, the minimum and maximum number of days required to make bolls was 49 and 59 days, repectively. Among those blossoms opening August 2, 3 and 4, the minimum number of days advanced to 60 , and the maximum had reached 75 days. Had data been secured for blossoms opening later in August and early September, the minimum and maximum for the making of the bolls would, without doubt, have reached much higher figures. It is probable that blossoms appearing during this period would have reached a maximum of 80 to 100 days in which to make their bolls.

Data secured for the following native and foreign cottons planted at the same time and in the same soil, indicates that some varieties make their bolls in a much shorter period of time than others. Blossoms opening on the days July 25 through July 31, matured their bolls as follows:

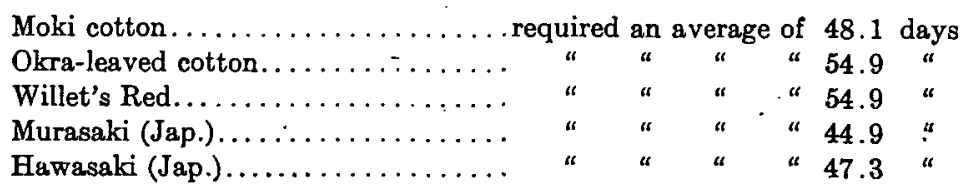

Forty-two was the minimum number of days required from the blossom to the cracking boll, in any of the varieties studied. This occurred in the Japanese variety Murasaki. The maximum for this Japanese variety for the same period was only 49 days, as compared with a minimum and maximum of 49 and 64 days,-respectively, for the Willet Red Leaf variety. These low figures for the Japanese variety are all the more striking, since it began blossoming considerably earlier than the Willet Red Leaf variety. It is probable that some of the small boll varieties of cotton make their bolls more quickly, under the same conditions, than the large boll varieties, as indicated above for the Moki cotton, and the two Japanese sorts.

In the north Georgia region, open cotton bolls begin to appear during the latter part of August and early September, 50 to 55 days, or less, after the earliest blossoms. Blossoms appearing later than about September 10 do not usually mature cotton. Yet the latest pickings extend 
into late November and December. This alone would indicate that these latest bolls of the season had required a much longer period to "make" than the first bolls. Notwithstanding this, it is difficult to see just why growers have so generally accepted the view that the earliest blossoms of the season take longest to "make" their bolls, and that there is a gradual shortening of this period as the later blossoms appear throughout the summer. A number have expressed the view that nature's wise provision must have ordained things in this way, in order that the plants may put on a maximum crop and at the same time better perpetuate themselves before cold weather.

One would reason that the growth-energy of the cotton plant must be greatest at the beginning of the blossoming season, and that this must normally diminish as the activities of nutrition, growth, etc., become taxed with a rapidly increasing crop of bolls toward the end of summer.

Blossoms appearing toward the middle of September are not likely to produce bolls. This is in part a response to the cooler days and nights and otherwise unfavorable weather conditions of this season. Moreover, the plants have nearly reached an equilibrium between boll production and the productive capacities of a particular arrangement of soil conditions. As a result of these soil and seasonal factors, the plants become so enfeebled in growth vigor that further boll production soon ceases.

The little-bolled cottons are earlier and therefore better suited than the big-bolled varieties to the short summers of the extreme edge of the cotton belt in northern Georgia and elsewhere. This character of earliness is probably not always owing to the fact that these may blossom earlier in the season, but also because they are able to "make" their crop of bolls in a shorter period of time.

\section{THE PROBLEM OF FIXATION IN COTTON HYBRIDS.}

By Prof. R. J. H. DeLonch, Experiment, Georgia.

When this problem is settled, there will be little difficulty in breeding a type of cotton for any specific purpose, if a combination of qualities shown in the present species and varieties will answer such purpose, for in a large number of hybrids, we could be assured of finding among the second and third year hybrids, almost every type ranging from one parent plant to the other. After we have found the ideal for which we are seeking, or breeding, fixing the type is the most important thing to consider, and selection is usually begun with this object, and selection 